\title{
Promoting Quality Use of Antibiotics in Dveleoping Countires: New Societal Approach
}

\section{Fahad Saleem* and Mohamed Azmi Hassali}

School of Pharmaceutical Sciences, Universiti Sains Malaysia, Penang, 11800, Malaysia

Irrational antibiotic use and increased resistance is a worldwide catastrophe. However, in comparison to other parts of the world, the phenomenon is recurrently reported from the Asian region. Alone in India and Pakistan only, 95\% of adults carry bacteria that are resistant to $\beta$-lactam antibiotics including carbapenems [1]. Within this context, poor sanitation, over rated agriculture and life stock use, overprescribing of antibiotics, patients' pressure and unregulated use of antibiotics are likely reasons of increased prevalence of antibiotic resistance in developing countries. Even though substantial concerns towards antibiotic resistance are raised by the World Health Organization, few countries have complied national data on antibiotic resistance and majority of the developing countries fail to track bacteria that are rated as 'threat' to public health [1]. Strict infection control measures to prevent survival and transfer of resistant bacteria is poorly regulated and increased resistance is becoming a foremost problem in developing countries [2].

In recent years, establishment of Antibiotic Stewardship Programs (ASPs) to promote quality use of antibiotics is recommended by US Centers for Disease Control and Prevention, European Centre for Disease Prevention and Control, European Medicines Agency and Institute of Medicine. ASPs require sufficient resources including members with antibiotic expertise who can monitor bacterial resistance, report antibiotic usage and provide education [3]. However, ASPs and related infrastructures are absent in majority of the healthcare organizations of the Asian region. Although the crisis of antibiotic resistance is widely discussed, the US government just recently approved the implementation of ASPs in hospitals nationwide [4]. Keeping this fact in mind, development and implementation of ASPs in developing countries in near future seem difficult because of poor infrastructure and lack of resources. Additionally, the political will in designing and implementing ASPs is also lacking, as ASPs do not provide a 'tangible benefit' to the policy makers and to the running governments in developing countries.

Consequently, the question is no longer whether to act, but how. Therefore, we hereby propose to adopt the MTC (Mosque, Temple and Church) approach to embark issues related to antibiotic use and resistance in developing countries. The Asian region is a conservative society where religion plays an important role in day-to-day activities and decisionmaking processes. Religion regulates and influences in determining and advocate health-related beliefs and behaviors [5]. Majority of the laws followed in developing countries have their foundations based on religious grounds and teachings. For that reasons, we strongly urge to utilize religious bodies, officials and leaders as a potential source of health educators. The religious bodies have the required infrastructure and most importantly, the 'influence' over people that can be utilized to promote quality use of antibiotics among general population. For example, the Roman Catholic Church is the largest non - government provider of health care services in the world with 5,500 hospitals and 65 percent of them are located in developing countries [6]. Additionally, leading religious gatherings of the world are also organized in the Asian region whereby people from all over the world come to perform their respective religious norms and practices. Such platforms are ideal for health education whereby services and sermons can be utilized to educate and inform people about the hazards of irrational antibiotic use and resistance. At the community level, monks, priests, pandits and muftis can prove to be a vital source of health education whereby they can provide continuous education to the public regarding issues related to antibiotic use and resistance.

However, for the practice applicability of MTC approach, support from the respective healthcare ministries to educate the religious institutes is essential. This can be achieved by using a cascade-training technique. Master trainers selected and appointed by the relevant healthcare ministries to educate targeted personals and institutes about knowledge, activities and skills related to antibiotic use and resistance is a valuable option. Once each trained group has its capacity raised to the satisfactory level, it can be utilized to educate another group of trainees. To ensure the success of the MTC approach, this tedious training and message delivery process requires close monitoring of healthcare professionals and a strong commitment of the healthcare ministries. However, once ensured by the healthcare professional, the message transferred through an influential religious entity of the society will promote quality use of antibiotics directly at the community level without financial and communal constrains.

One thing is for sure; the crisis of antibiotic resistance will continue to grow in future. Therefore, in addition to the recommended strategies, new social approaches are needed to address issues related to antibiotic resistance. By using the MTC approach, people will realize that individual choices and actions contribute to the wellbeing or deterioration of the environment. Until ASPs in developing countries are established, the MTC approach aiming to revise the way antibiotics are used can provide assistance in promoting quality use of antibiotics.

\section{References}

1. Reardon S (2014) Antibiotic resistance sweeping developing world. Nature 509: 141-142.

2. Lopardo G, Titanti P, Berdiñas V Barcelona L, Curcio D (2011) Antimicrobial stewardship program in a developing country: The epidemiological barrier. Rev Panam Salud Publica 30: 667-668.

3. Spellberg B, Srinivasn A, Chambers FH (2013) New societal approaches to empowering antibiotic stewardship. J Am Med Assoc 15: 1229-1230.

4. Executive Office of the President. Report to the President on combating antibiotic resistance.

5. Harwood A (1981) Ethnicity and medical care. Boston: Harvard University Press.

6. Agnew J (2010) Deus vult: The geopolitics of the Catholic Church. Geopolitics 15: $39-61$.

*Corresponding author: Fahad Saleem, School of Pharmaceutical Sciences, Universiti Sains Malaysia, Penang, 11800, Malaysia, Tel: 0060124003956; E-mail: fahaduob@gmail.com

Received April 11, 2016; Accepted April 12, 2016; Published April 14, 2016

Citation: Saleem F, Hassali MA (2016) Promoting Quality Use of Antibiotics in Dveleoping Countires: New Societal Approach. Health Econ Outcome Res Open Access 2: e103. doi: 10.4172/2471-268x/1000e103

Copyright: $\odot 2016$ Saleem F, et al. This is an open-access article distributed under the terms of the Creative Commons Attribution License, which permits unrestricted use, distribution, and reproduction in any medium, provided the original author and source are credited. 